\title{
Genetic tests in children with steroid-resistant nephrotic syndrome
}

\author{
Hae II Cheong ${ }^{1,2}$ (i) \\ 'Department of Pediatrics, Seoul National University Children's Hospital, Seoul, Republic of Korea \\ ${ }^{2}$ Kidney Research Institute, Medical Research Center, Seoul National University College of Medicine, Seoul, Republic of Korea
}

\begin{abstract}
Steroid-resistant nephrotic syndrome (SRNS) is a common cause of chronic kidney disease in children, and a considerable number of patients progress to end-stage renal disease. SRNS is a highly heterogeneous disorder, both clinically and genetically, and more than 50 monogenic causes of SRNS, including isolated and syndromic forms, have been identified. Recent large-cohort studies indicate that at least $30 \%$ of childhood-onset SRNS cases are genetic. The benefits of definitive molecular diagnosis by genetic testing include the avoidance of unnecessary and potentially harmful diagnostic procedures (e.g., kidney biopsy) and treatment (e.g., steroid and immunosuppressants), detection of rare and potentially treatable mutations (e.g., coenzyme Q10 biosynthesis pathway defect), prediction of prognosis (e.g., posttransplant recurrence), and providing precise genetic counseling. Furthermore, the identification of novel disease-causing genes could provide new insights into the pathogenic mechanisms of SRNS. Therefore, whenever accessible and affordable, genetic testing is recommended for all pediatric patients with SRNS, and should certainly be performed in patients with a higher probability of genetic predisposition based on genotype-phenotype correlation data. The genetic testing approach should be determined for each patient, and clinicians should, therefore, be aware of the advantages and disadvantages of methods currently available, which include Sanger sequencing, gene panel testing, and whole-exome or whole-genome sequencing. Importantly, the need for precise and thorough phenotyping by clinicians, even in the era of genomics, cannot be overemphasized. This review provides an update on recent advances in genetic studies, a suggested approach for the genetic testing of pediatric patients with SRNS.
\end{abstract}

Keywords: High-throughput nucleotide sequencing, Phenocopy, Reverse phenotyping, Sanger sequencing, Steroidresistant nephrotic syndrome

Received January 3, 2020; Revised February 7, 2020;

Accepted February 19, 2020

Edited by Soo Wan Kim, Chonnam National University, Gwangju, Republic of Korea

\section{Correspondence: Hae ll Cheong}

Department of Pediatrics, Seoul National University Children's Hospital, 101 Daehak-ro, Jongno-gu, Seoul 03080, Republic of Korea. E-mail:cheonghi@snu.ac.kr

Copyright (c) 2020 by The Korean Society of Nephrology

(a) This is an open-access article distributed under the terms of the Creative Commons Attribution Non-Commercial License (http://creativecommons. org/licenses/by-nc-nd/4.0/), which permits unrestricted non-commercial use, distribution, and reproduction in any medium, provided the original work is properly cited.

\section{Introduction}

The majority of pediatric patients with idiopathic nephrotic syndrome respond well to steroids. However, $10 \%$ to $20 \%$ of affected children have steroid-resistant nephrotic syndrome (SRNS) [1]. Most SRNS cases are accompanied by focal segmental glomerulosclerosis (FSGS) and progress to end-stage renal disease (ESRD). To date, more than 50 monogenic causes of SRNS/FSGS have been identified, and novel causative genes are continually being discovered [2].

Traditional Sanger sequencing, the classic chain-termination method of DNA sequencing, is the 'gold standard', providing high specificity and sensitivity in the genetic 
Table 1. Genetic studies in large cohorts of pediatric patients with steroid-resistant nephrotic syndrome

\begin{tabular}{|c|c|c|c|c|c|c|}
\hline & $\begin{array}{c}\text { Trautmann et al } \\
\text { [5] (2015) } \\
\end{array}$ & $\begin{array}{c}\text { Sadowski et al } \\
\text { [3] (2015) }\end{array}$ & $\begin{array}{c}\text { Bierzynska et al } \\
{[2](2017)} \\
\end{array}$ & $\begin{array}{l}\text { Wang et al } \\
{[6](2017)}\end{array}$ & $\begin{array}{c}\text { Warejko et al } \\
\text { [4] (2018) }\end{array}$ & $\begin{array}{l}\text { Nagano et al } \\
\text { [7] (2020) }\end{array}$ \\
\hline Country & International & International & United Kingdom & China & International & Japan \\
\hline Modality & GP (31 genes) & GP (27 genes) & WES (53 genes) & GP (28 genes) & WES & GP (60 genes) \\
\hline Detection rate $^{a}$ & $277 / 1,174(23.6)$ & $526 / 1,783(29.5)$ & $49 / 187(26.2)$ & $34 / 120(28.3)$ & $85 / 300(28.3)$ & $69 / 230(30.0)$ \\
\hline \multirow[t]{5}{*}{$\begin{array}{l}\text { Commonly } \\
\text { mutated genes }^{\text {b }}\end{array}$} & $\begin{array}{l}\text { NPHS2, } \\
138 / 277(49.8)\end{array}$ & $\begin{array}{l}\text { NPHS2, } \\
177 / 526(33.7)\end{array}$ & $\begin{array}{l}\text { NPHS1, } \\
\text { 14/49 (28.6) }\end{array}$ & $\begin{array}{l}\text { COQ8B, } \\
\text { 8/34 (23.5) }\end{array}$ & $\begin{array}{l}\text { NPHS1, } \\
\text { 13/85 (15.3) }\end{array}$ & $\begin{array}{l}\text { WT1, } \\
17 / 69(24.6)\end{array}$ \\
\hline & $\begin{array}{l}\text { WT1, } \\
\quad 48 / 277 \text { (17.3) }\end{array}$ & $\begin{array}{l}\text { NPHS1, } \\
\text { 131/526 (24.9) }\end{array}$ & $\begin{array}{l}\text { NPHS2, } \\
12 / 49 \text { (24.5) }\end{array}$ & $\begin{array}{l}\text { NPHS1, } \\
\text { 7/34 (20.6) }\end{array}$ & $\begin{array}{l}\text { PLCE1, } \\
\text { 11/85 (12.9) }\end{array}$ & $\begin{array}{l}\text { NPHS1, } \\
\text { 8/69 (11.6) }\end{array}$ \\
\hline & $\begin{array}{l}\text { NPHS1, } \\
\quad 41 / 277 \text { (14.8) }\end{array}$ & $\begin{array}{l}\text { WT1, } \\
85 / 526(16.2)\end{array}$ & $\begin{array}{l}\text { WT1, } \\
\text { 4/49 (8.2) }\end{array}$ & $\begin{array}{l}\text { WT1, } \\
7 / 34 \text { (20.6) }\end{array}$ & $\begin{array}{l}\text { NPHS2, } \\
8 / 85(9.4)\end{array}$ & $\begin{array}{l}\text { INF2, } \\
8 / 69 \text { (11.6) }\end{array}$ \\
\hline & $\begin{array}{l}\text { SMARCAL1, } \\
\text { 12/277 (4.3) }\end{array}$ & $\begin{array}{l}\text { PLCE1, } \\
37 / 526(7.0)\end{array}$ & $\begin{array}{l}\text { NUP107, } \\
\text { 4/49 (8.2) }\end{array}$ & $\begin{array}{l}\text { NPHS2, } \\
\text { 4/34 (11.8) }\end{array}$ & $\begin{array}{l}\text { SMARCAL1, } \\
8 / 85(9.4)\end{array}$ & $\begin{array}{l}\text { TRPC6, } \\
\text { 7/69 (10.1) }\end{array}$ \\
\hline & $\begin{array}{l}\text { PLCE1, } \\
\text { 10/277 (3.6) }\end{array}$ & $\begin{array}{l}\text { LAMB2, } \\
\text { 20/526 (3.8) }\end{array}$ & $\begin{array}{l}\text { TRPC6, } \\
3 / 49(6.1)\end{array}$ & $\begin{array}{l}L M X 1 B \\
\text { 2/34 (5.9) }\end{array}$ & $\begin{array}{l}\text { LAMB2, } \\
\quad 6 / 85(7.1)\end{array}$ & $\begin{array}{l}\text { LAMB2, } \\
\quad 6 / 69(8.7)\end{array}$ \\
\hline
\end{tabular}

Data are presented as number/total number (\%).

$\mathrm{GP}$, gene panel; WES, whole-exome sequencing.

${ }^{a}$ Overall mutation detection rate. ${ }^{b}$ Parentheses denote the percentage of total patients with mutations.

diagnosis of hereditary diseases. However, given the large genetic heterogeneity of SRNS, using Sanger sequencing entails significant cost and effort, unless a single or few disease-relevant genes can be identified clinically. However, recent advances in next-generation sequencing (NGS) have provided a revolutionary new approach for genetic diagnosis in terms of cost and effectiveness by allowing a panel of candidate genes or whole genes to be sequenced simultaneously. Mutations have been detected in approximately $30 \%$ of childhood-onset SRNS cases, according to large-cohort studies using NGS (Table 1) [2-7]. Thus, clinicians must select the best diagnostic tool for patients with a suspected genetic disorder.

This review gives an update on recent advances in genetic studies, provides a suggested approach for genetic testing, and describes the potential translation of genetic information into clinical diagnosis and treatment in pediatric patients with SRNS.

\section{Genotype-phenotype correlations in monogenic SRNS}

Currently, in the Online Mendelian Inheritance in Man database (OMIM, https://www.ncbi.nlm.nih.gov/ omim), 21 genes are listed under the category of nephrotic syndrome (NPHS1-21) and nine genes are listed under the FSGS category (FSGS1-9) (Table 2). These genes are expressed either exclusively or predominantly by podocytes. Most diseases within the category of NPHS have an autosomal recessive mode of inheritance, high penetrance, and earlier disease onset. Conversely, most diseases within the category of FSGS have an autosomal dominant mode of inheritance, incomplete penetrance, and later disease onset. In addition, many other genes are listed as causative genes for isolated or syndromic forms of SRNS or FSGS (Table 3).

\section{Age of onset}

The likelihood of detecting a causative mutation is inversely related to the age of disease onset in patients with SRNS. In one large-cohort study [3], the mutational detection rate in patients with disease onset within the first 3 months of life (congenital nephrotic syndrome) and at age 4 to 12 months (infantile nephrotic syndrome) was $69.4 \%$ and $49.7 \%$, respectively $(61.3 \%$ in the first year combined). This fraction decreased to $25.3 \%$ at age 1 to 6 years, $17.8 \%$ at age 7 to 12 years, and $10.8 \%$ at age 13 to 18 years.

The major disease-causing genes for congenital nephrotic syndrome are NPHS1, NPHS2, WT1, and LAMB2, which account for $85 \%$ of patients in a European study and $93 \%$ in a Korean study $[8,9]$. PLCE1 is another gene that is often mutated in early-onset SRNS and is typically associated with histological lesions of diffuse mesangial sclerosis (DMS) [10]. 
Table 2. Diseases under categories of nephrotic syndrome (NPHS) and focal segmental glomerulosclerosis (FSGS) in the Online Mendelian Inheritance in Man (OMIM)

\begin{tabular}{|c|c|c|c|c|}
\hline Disease & Gene & Inheritance & OMIM number $^{\mathrm{a}}$ & Proteins \\
\hline NPHS1 & NPHS1 & AR & 256300 & Nephrin \\
\hline NPHS2 & $P D C N$ & AR & 600995 & Podocin \\
\hline NPHS3 & PLCE1 & AR & 610725 & Phospholipase c, epsilon-1 \\
\hline NPHS4 & WT1 & $A D$ & 256370 & WT1 transcription factor \\
\hline NPHS5 & LAMB2 & AR & 614199 & Laminin, beta-2 \\
\hline NPHS6 & PTPRO & AR & 614196 & Protein-tyrosine phosphatase, receptor-type, 0 \\
\hline NPHS7 & $D G K E$ & AR & 615008 & Diacylglycerol kinase, epsilon, 64-kDa \\
\hline NPHS8 & ARHGDIA & AR & 615244 & Rho GDP-dissociation inhibitor alpha \\
\hline NPHS9 & COQ8B & AR & 615573 & Coenzyme Q8B \\
\hline NPHS10 & EMP2 & AR & 615861 & Epithelial membrane protein 2 \\
\hline NPHS11 & NUP107 & AR & 616730 & Nucleoporin, 107-kDa \\
\hline NPHS12 & NUP93 & AR & 616892 & Nucleoporin, 93-kDa \\
\hline NPHS13 & NUP205 & AR & 616893 & Nucleoporin, 205-kDa \\
\hline NPHS14 & SGPL1 & AR & 617575 & Sphingosine-1-phosphate lyase 1 \\
\hline NPHS15 & MAGI2 & AR & 617609 & Membrane-associated guanylate kinase, WW and PDZ domain-containing, 2 \\
\hline NPHS16 & KANK2 & AR & 617783 & KN motif- and Ankyrin repeat domain-containing protein 2 \\
\hline NPHS17 & NUP85 & AR & 618176 & Nucleoporin, 85-kDa \\
\hline NPHS18 & NUP133 & AR & 618177 & Nucleoporin, 133-kDa \\
\hline NPHS19 & NUP160 & AR & 618178 & Nucleoporin, 160-kDa \\
\hline NPHS20 & $T B C 1 D 8 B$ & $\mathrm{XL}$ & 301028 & TBC1 domain family, member 8B \\
\hline NPHS21 & AVIL & AR & 618594 & Advillin \\
\hline FSGS1 & ACTN4 & $A D$ & 603278 & Actinin, alpha 4 \\
\hline FSGS2 & TRPC6 & $A D$ & 603965 & Transient receptor potential cation channel, subfamily C, member 6 \\
\hline FSGS3 & $C D 2 A P$ & $A R / A D$ & 607832 & CD2-associated protein \\
\hline FSGS4 & APOL1 & AR & 612551 & Apolipoprotein L-I \\
\hline FSGS5 & INF2 & $A D$ & 613237 & Inverted formin 2 \\
\hline FSGS6 & MY01E & AR & 614131 & Myosin IE \\
\hline FSGS7 & PAX2 & $A D$ & 616002 & Paired box protein 2 \\
\hline FSGS8 & ANLN & $A D$ & 616032 & Actin binding protein anillin \\
\hline FSGS9 & CRB2 & AR & 616220 & Crumbs cell polarity complex component 2 \\
\hline
\end{tabular}

$A D$, autosomal dominant; $A R$, autosomal recessive.

${ }^{\text {a}}$ Phenotype number.

NPHS2, which encodes podocin, is the gene most commonly mutated in patients with disease onset between 4 months and 18 years in most Western countries [2,3,11]. However, the rate of NPHS2 mutation as a cause for SRNS is rare in certain ethnic groups, including Korean, Chinese, and Japanese populations $[6,12,13]$. WT1 is also commonly mutated, accounting for approximately $6 \%$ of sporadic SRNS cases in childhood $[12,14,15]$. WT1 mutations can manifest at any age as either isolated or syndromic forms of SRNS [12,14]. One study found that mutations in WT1 show a biphasic distribution, with a large peak at 4 to 12 months age at onset and a second smaller peak beyond 18 years [3].

While most autosomal recessive SRNS cases manifest in early childhood, autosomal dominant SRNS typically present in adolescence or adulthood. The major dominant genes that manifest in late-onset SRNS include ACTN4, TRPC6, and INF2 [3]. In a study of adult patients with FSGS [16], the overall rate of genetic diagnosis was $11 \%$, including $55 \%$ of the total detected with mutations in $C O L 4 A 3-5,40 \%$ in podocyte genes, and $5 \%$ in congenital anomalies of the kidney and urinary tract genes. 
Table 3. Syndromic forms of steroid-resistant nephrotic syndrome/focal segmental glomerulosclerosis

\begin{tabular}{|c|c|c|c|}
\hline Gene & Inheritance & OMIM number $^{a}$ & Disease \\
\hline ALG1 & AR & 608540 & Congenital disorder of glycosylation, type Ik \\
\hline ARHGDIA & AR & 615244 & Seizures, cortical blindness \\
\hline$C D 151$ & AR & 609057 & Pretibial epidermolysis bullosa and deafness \\
\hline COQ2 & AR & 607426 & Coenzyme Q10 deficiency, primary, 1; encephalopathy \\
\hline COQ6 & AR & 614650 & Coenzyme Q10 deficiency, primary, 1; deafness \\
\hline CUBN & AR & 261100 & Megaloblastic anemia-1, Finnish type \\
\hline DGKE & AR & 615008 & Atypical hemolytic uremic syndrome \\
\hline INF2 & $A D$ & 614455 & Charcot-Marie-Tooth disease, dominant intermediate $\mathrm{E}$ \\
\hline ITGA3 & AR & 614748 & Epidermolysis bullosa, interstitial lung disease \\
\hline ITGB4 & AR & 226650 & Epidermolysis bullosa, junctional, non-Herlitz type \\
\hline LAMB2 & AR & 609049 & Pierson syndrome \\
\hline LAGE3 & $\mathrm{XR}$ & 301006 & Galloway-Mowat syndrome 2, X-linked \\
\hline LCAT & AR & 245900 & Norum disease (classical familial lecithin:cholesterol acyltransferase deficiency) \\
\hline LMNA & $A D$ & 151660 & Lipodystrophy, familial partial, type 2 \\
\hline$L M X 1 B$ & $A D$ & 161200 & Nail-patella syndrome \\
\hline MAFB & $A D$ & 166300 & Multicentric carpotarsal osteolysis \\
\hline MTTL1 & Mt & 540000 & MELAS syndrome \\
\hline MYH9 & $A D$ & 155100 & $\begin{array}{l}\text { Macrothrombocytopenia and granulocyte inclusions with or without nephritis or } \\
\text { sensorineural hearing loss (Epstein syndrome, Fechtner syndrome) }\end{array}$ \\
\hline NUP107 & AR & 618348 & Galloway-Mowat syndrome 7 \\
\hline NUP133 & AR & 618349 & Galloway-Mowat syndrome 8 \\
\hline NXF5 & $\mathrm{XR}$ & & Co-segregating heart block \\
\hline OSGEP & AR & 617729 & Galloway-Mowat syndrome 3 \\
\hline PAX2 & $A D$ & 120330 & Papillorenal syndrome \\
\hline PDSS2 & AR & 614652 & Coenzyme Q10 deficiency, primary, 3; Leigh syndrome \\
\hline PMM2 & AR & 212065 & Congenital disorder of glycosylation, type la \\
\hline PODXL & AR & & Congenital omphalocele \\
\hline SCARB2 & AR & 254900 & Epilepsy, progressive myoclonic 4, with or without renal failure \\
\hline SMARCAL1 & AR & 242900 & Schimke immuno-osseous dysplasia \\
\hline TP53RK & AR & 617730 & Galloway-Mowat syndrome 4 \\
\hline TPRKB & AR & 617731 & Galloway-Mowat syndrome 5 \\
\hline WDR4 & AR & 618347 & Galloway-Mowat syndrome 6 \\
\hline WDR73 & AR & 251300 & Galloway-Mowat syndrome 1 \\
\hline WT1 & $A D$ & 194080,136680 & Denys-Drash syndrome, Frasier syndrome \\
\hline ZMPSTE24 & AR & 608612 & Mandibuloacral dysplasia with type B lipodystrophy \\
\hline
\end{tabular}

AD, autosomal dominant; AR, autosomal recessive; MELAS, mitochondrial encephalopathy, lactic acidosis, and stroke-like episodes; Mt, mitochondrial; XR, X-linked recessive.

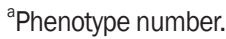

\section{Renal pathology}

Although most pediatric patients with SRNS display lesions of FSGS, other types of lesions may also be involved, such as minimal change lesions, mesangial proliferative glomerulonephritis, and DMS [5].

In a report from the SRNS Study Group [3], renal biopsy patterns were found to differ according to age group; DMS was a frequent finding $(26.9 \%)$ in infants, whereas FSGS was seen in more than $90 \%$ of individuals with the onset of proteinuria at 7 to 25 years. In addition, in individuals with mutations in genes (WT1, PLCE1, LAMB2, and NPHS1) mostly detected in patients with earlier onset, DMS was frequent $(23.1 \%, 17.8 \%, 13.6 \%$, and $4.9 \%$ re- 
spectively), whereas mutations in other genes commonly detected in patients with later onset never led to DMS. These findings suggest that DMS, lying on the opposite side of FSGS on a spectrum of shared pathogenesis, represents a developmental glomerular phenotype of immature glomeruli $[3,17]$.

Interestingly, some patients with primary coenzyme Q10 deficiency (COQ2 or COQ6 mutations) show collapsing glomerulopathy [18-20].

\section{Syndromic SRNS}

Several different syndromic SRNS with typical extrarenal manifestations have been reported (Table 3). These diseases are typically due to mutations in genes that encode nuclear proteins/transcription factors (WT1, LMX1B, SMARCAL1, PAX2, LMNA, MAFB, and WDR73), glomerular basement membrane and adhesion proteins (LAMB2, ITGA3, and ITGB4), actin cytoskeleton components (MYH9 and INF2), lysosomal (SCARB2) proteins, and mitochondrial proteins (COQ2, COQ6, and PDSS2), but not slit diaphragm-associated proteins (NPHS1, NPHS2, PLCE1, and TRPC6) [21].

If a patient shows typical extrarenal manifestations, it is highly likely that the disease-relevant gene mutation will be identified. However, a significant fraction of patients with mutations in syndromic genes either do not manifest or manifest only mild or ambiguous extrarenal phenotypes. Thus, the absence of typical extrarenal manifestations does not guarantee an absence of syndromic gene mutations.

Mutations in at least eight genes (PDSS1, PDSS2, COQ2, COQ4, COQ6, COQ8A, COQ8B, and COQ9) have been reported to cause primary coenzyme Q10 deficiency in humans [22], and mutations in four of those genes can cause renal phenotypes, either syndromic SRNS (PDSS2, COQ2, and COQ6) $[20,23,24]$ or isolated SRNS (COQ8B) [25]. Early and accurate diagnosis of primary coenzyme Q10 deficiency is vital because starting high-dose coenzyme Q10 supplementation at an early stage can result in remission or amelioration of proteinuria at least $[23,25,26]$.

\section{Ethnic differences}

Similar to most genetic disorders, hereditary SRNS shows ethnic differences. Compared to other ethnicities, the most striking feature within the Korean populations is a very low prevalence of NPHS2 mutations [12]. This finding is also common in Chinese and Japanese populations $[6,13]$. On the other hand, mutations in NUP107, COQ8B, and COQ6 are relatively more common in Korea $[19,27,28]$.

\section{Benefits of genetic testing}

Patients with a rare disease often face a difficult journey to diagnosis, commonly termed a 'diagnostic odyssey', which includes moving from clinician to clinician, multiple misdiagnoses, unnecessary tests, and incorrect treatment. An early genetic diagnosis may thus help to avoid this diagnostic odyssey [29]. Accurate genetic diagnosis in patients with SRNS can also be beneficial in several other ways. First, genetic diagnosis is essential for genetic counseling. Second, detection of certain mutations enables prediction and further screening of renal and extrarenal comorbidities that may have otherwise taken longer to diagnose, i.e. 'reverse phenotyping.' Early detection and disease monitoring of certain extrarenal phenotypes may help to address the potential of serious complications, such as the development of Wilms' tumor or gonadoblastoma in patients with WT1 mutations $[14,30]$. Third, genetic diagnosis affects the future treatment plan. Almost all genetic forms of SRNS do not respond to conventional steroids or immunosuppressants, therefore an accurate genetic diagnosis could make it possible to avoid such unnecessary and potentially harmful treatments. In addition, genetic testing can detect rare mutations that may be amenable to treatment such as mutations in the coenzyme Q10 biosynthesis pathway $[23,25,26]$. Finally, in patients preparing for a kidney transplant, the likelihood of posttransplant recurrence of FSGS can be predicted to be very low by the presence of genetic mutations $[5,11,31]$. However, it is known that the recurrence rate of proteinuria/nephrotic syndrome in a graft kidney is about $30 \%$ in patients homozygous for the Fin-major mutation in NPHS1, and approximately $70 \%$ of them have measurable anti-nephrin antibodies [32]. The Fin-major mutation in NPHS1 has never been reported in the Korean population. In addition, in patients with autosomal dominant mutations, family member kidney donor candidates should also undergo genetic test- 
ing because they could be harboring a disease-causing mutation despite being clinically asymptomatic, due to low penetrance of the mutated genes. These individuals could go on to develop clinical symptoms after kidney donation.

\section{Indications for genetic testing}

In clinical practice, a kidney biopsy is recommended for pediatric patients with nephrotic syndrome who do not respond to initial steroid treatment in order to achieve a pathological diagnosis and create an effective future treatment plan. A genetic diagnosis may provide a more clear-cut assessment of the disorder than a pathological diagnosis. Therefore, whenever accessible and affordable, genetic testing should be performed in conjunction with, or even instead of, a kidney biopsy in all pediatric SRNS patients. However, when such an inclusive approach is not possible, genetic testing should be performed as a priority on the basis of certain indications to stratify the likelihood of a genetic cause, after considering cost-effectiveness [20].

Although genetic testing is recommended for all pediatric patients with SRNS, it is frequently performed in clinical practice in those patients with 1) early age at onset, especially congenital ( $<3$ months of age) or infantile ( 4 month to 1 year of age) onset, 2 ) a family history of SRNS or consanguinity, 3) presence of typical extrarenal manifestations of syndromic diseases, 4) lack of response to multiple drugs, 5) progression to chronic kidney disease or ESRD, and 6) preoperative evaluation for kidney transplantation.

\section{Modality of genetic testing}

The modality of genetic testing is changing rapidly as a consequence of rapid advances in NGS. In addition to traditional Sanger sequencing, three NGS approaches for genetic diagnosis are now available in the clinical setting: 1) gene panels, 2) whole-exome sequencing (WES), and 3) whole-genome sequencing (WGS).

\section{Sanger sequencing}

Although there has been a rapid increase in the use of NGS, Sanger sequencing is still regarded as the gold stan- dard, providing high specificity and sensitivity for genetic diagnosis. Sanger sequencing can be used very effectively with a single or few candidate genes, especially small-size genes, which are identified by genotype-phenotype correlation data. For example, mutational screening for four candidate genes (NPHS1, NPHS2, WT1, and LAMB2) will provide a genetic diagnosis in more than $85 \%$ of congenital nephrotic syndrome cases $[8,9]$. As another example, in ethnic groups with a higher prevalence of NPHS2 mutations, the sum of mutations in three common diseasecausing genes (NPHS1, NPHS2, and WT1) account for over $70 \%$ of total mutations detected in pediatric patients with SRNS $[3,5,33]$. Given that NPHS1 mutations are predominantly associated with early-onset SRNS, pediatric patients with late-onset SRNS should be screened for NPHS2 (the entire coding sequence of 8 exons) and WT1 (exons 8 and 9, the hot spots for mutations) [34]. However, such recommendations cannot be applied in Korea, due to the very low prevalence of NPHS2 mutations [12]. Disease-relevant genes may also be suspected clinically in patients who present with a typical extrarenal phenotype associated with a syndromic form of SRNS (Table 3).

In addition, Sanger sequencing can be used to confirm variants detected by NGS and can complement NGS by filling in low-coverage and no-coverage regions due to sequence homology with pseudogenes, high guaninecytosine (GC)-rich content, highly repetitive regions, and other sequence complexities [35].

\section{Gene panel testing}

SRNS is a highly heterogeneous disorder, with more than 60 known disease-causing genes. When a clinical evaluation of a patient with SRNS cannot elicit either a single or a few disease-relevant genes, gene-by-gene Sanger sequencing can be replaced by gene panel analysis, where all protein-coding exons of multiple candidate genes are tested simultaneously using high-throughput polymerase chain reaction amplification and sequencing approaches. The gene panel can be designed specifically as an indication-driven test by including genes known to be associated with a certain phenotype or disease group, such as SRNS or proteinuria. Gene panel analysis is currently considered the most cost-effective approach for indication-driven mutation analysis [36].

Gene panel testing can also be used to analyze genes, 
which are too large for Sanger sequencing, such as the COL4A3-5 genes that cause Alport syndrome. Importantly, mutations in syndromic genes are observed in a significant fraction of patients with no or mild/atypical extrarenal phenotypes. In these cases, the suspected underlying genetic syndrome cannot be identified clinically, but gene panel testing is able to detect the diseasecausing mutations.

Compared to WES or WGS, the advantages of gene panel testing include lower cost, overall higher exon coverage, no incidental findings in genes unrelated to the disease of interest, and detection of fewer variants of unknown significance. However, to achieve $100 \%$ coverage, Sanger fill-in and/or complementary assays such as targeted gene arrays to detect deletions/duplications are required. The disadvantages of gene panel testing include rapidly outdated gene panels due to the continuous discovery of novel disease-causing genes, and the existence of novel or phenocopy genes that will not be included in the panel and therefore will not be detected. A phenocopy is defined as "a phenotypic trait or disease that resembles the trait expressed by a particular genotype, but in an individual who is not a carrier of that genotype" [37]. For example, patients with hereditary renal diseases not belonging to SRNS, such as Alport syndrome, Dent disease, renal-coloboma syndrome, and Fabry disease, can manifest proteinuria or SRNS as the only evident clinical sign at disease onset or even later [16,38-41]. These cases are often misdiagnosed as isolated SRNS, but gene panel testing for SRNS reveals a negative result. Such conditions are referred to as phenocopies of hereditary SRNS [42].

\section{Whole-exome sequencing}

WES refers to the sequencing of the entire exome, i.e., sequencing of all protein-coding regions that make up $1 \%$ to $2 \%$ of the whole genome. With continual reductions in sequencing cost and the development of bioinformatics, WES has become a more efficient and unbiased approach to genetic diagnosis than gene panel testing. Because WES covers not only known candidate genes but also whole genes, it can identify novel disease-causing genes and thus expand the genetic heterogeneity of SRNS.

A current limitation in the clinical application of WES is that it cannot offer complete coverage of all exons, which results in the dropout of several critical exons. For instance, certain genomic regions, which have sequence homology with pseudogenes, high GC-rich content, highly repetitive regions, and other sequence complexities, are difficult to amplify, and analyzing such regions may give false-negative or false-positive results. Although the complementary Sanger fill-in of these genomic regions refractory to NGS confers high clinical sensitivity and specificity on gene panel testing, practically, such fill-in is not feasible for WES because the proportion of problematic regions increases significantly when a huge region is targeted (62 Mb; $1 \%$ to $2 \%$ of the whole genome) [36]. Another limitation that hinders the widespread application of WES is the generation of large amounts of data and insufficient bioinformatics support to manage the data. To overcome these limitations, filtering the exome information via analysis of an in silico panel of genes associated with the disease of interest will give similar results to gene panel testing. The analysis can then be extended in response to negative findings in the first-line analysis or to search for novel disease-causing genes [21,42]. In a recent study of 64 young patients diagnosed with SRNS by Landini et al [43], the exome results were filtered in silico for 298 genes related to chronic kidney disease, including but not limited to SRNS-related genes. They found disease-causing variants in podocytopathy genes typically associated with SRNS and FSGS in 19 patients $(30 \%)$ as well as pathogenic mutations in phenocopy genes, including COL4A3-5 (Alport syndrome), CLCN5 (Dent disease), PAX2 (renal-coloboma syndrome), and GLA (Fabry disease), in 18 patients who were clinically diagnosed with, and treated for, SRNS. Post hoc thorough 'reverse phenotyping' revealed the presence of distinct extrarenal phenotypes typical of the genetic diagnoses in all patients and/or first-degree relatives [43]. In other words, the combination of a WES-based diagnostic workflow for an extended panel of nephropathy-related genes with reverse phenotyping of patients and their families doubled the diagnostic rate for genetic diagnosis underlying SRNS from $30 \%$ to $60 \%$ [43].

\section{Whole-genome sequencing}

WGS can provide the complete data set of an individual's genome by sequencing the entire genome. Compared to WES, it has the advantage of potentially improv- 


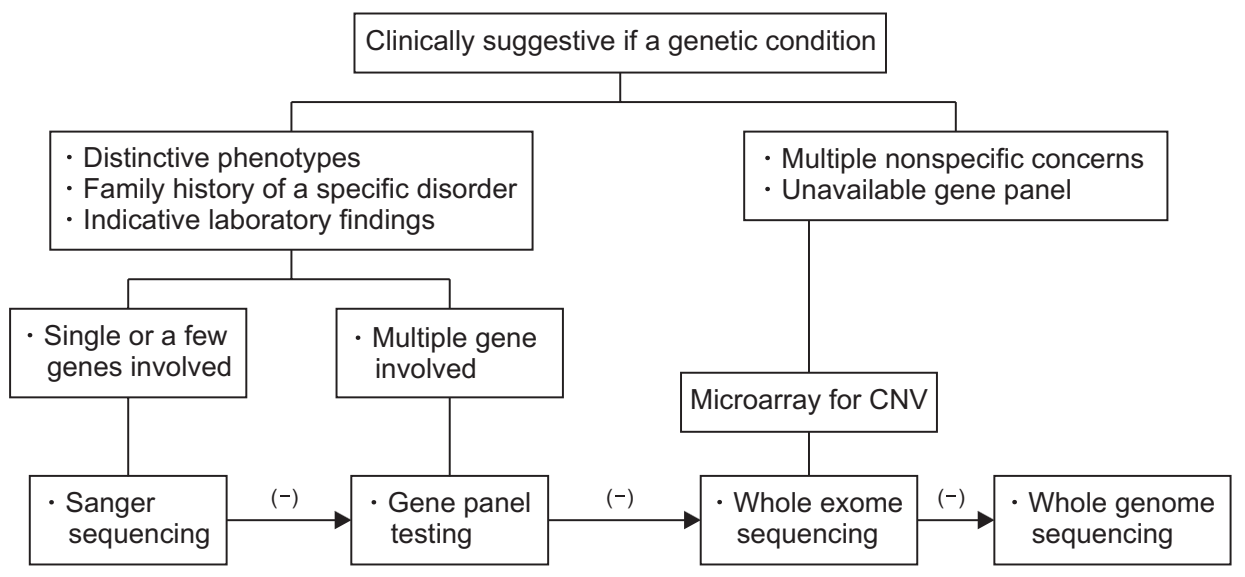

Figure 1. Algorithm for the molecular genetic testing in pediatric patients with steroid-resistant nephrotic syndrome. This algorithm is modified from the study by Xue et al [35].

CNV, copy number variation. ing exon, regulatory, and intronic region coverage, and improving the analysis of copy number and structural rearrangements. However, due to the high cost and long analytic period with a substantial amount of data generation, WGS is currently recommended only as a secondline test. A similar approach to that used with WES can also be used with WGS, i.e., analyzing a panel of relevant genes only.

\section{Algorithm for genetic testing}

Currently, there are no universal guidelines for the mutation screening of children with SRNS. Clinicians should consider the clinical usefulness, relevance, availability, and cost-effectiveness when they direct genetic testing for pediatric patients with SRNS. Figure 1 shows an algorithm for genetic testing, which is modified from the study by Xue et al [35].

\section{Conclusions}

SRNS is a genetically and phenotypically heterogeneous disorder, and more than 60 monogenic causes of SRNS have been identified. At least $30 \%$ of childhood-onset SRNS cases are caused by a genetic mutation. Currently used genetic testing methods for SRNS include Sanger sequencing, panel gene testing, WES, and WGS, each of which has advantages and disadvantages. At present, clinical phenotyping combined with targeted NGS panel analysis is the most cost-effective and clinically useful approach for the mutational screening of SRNS [21] and should be used whenever accessible and affordable. However, decisions should be made based on the specific patient and medical center. Most importantly, even in the era of genomics, precise and thorough phenotyping by clinicians remains essential for an accurate genetic diagnosis, including selection of the appropriate genetic testing method and interpretation of results [42].

\section{Conflicts of interest}

The author has no conflicts of interest to declare.

\section{Acknowledgments}

This research was supported by a grant from the Korea Health Technology Research \& Development Project through the Korea Health Industry Development Institute, funded by the Ministry of Health \& Welfare, Republic of Korea (grant number: HI18C0013).

\section{References}

[1] Noone DG, Iijima K, Parekh R. Idiopathic nephrotic syndrome in children. Lancet 2018;392:61-74.

[2] Bierzynska A, McCarthy HJ, Soderquest K, et al. Genomic and clinical profiling of a national nephrotic syndrome cohort advocates a precision medicine approach to disease management. Kidney Int 2017;91:937-947.

[3] Sadowski CE, Lovric S, Ashraf S, et al. A single-gene cause in $29.5 \%$ of cases of steroid-resistant nephrotic syndrome. $J$ Am Soc Nephrol 2015;26:1279-1289.

[4] Warejko JK, Tan W, Daga A, et al. Whole exome sequencing of patients with steroid-resistant nephrotic syndrome. Clin J Am Soc Nephrol 2018;13:53-62.

[5] Trautmann A, Bodria M, Ozaltin F, et al.; PodoNet Con- 
sortium. Spectrum of steroid-resistant and congenital nephrotic syndrome in children: the PodoNet registry cohort. Clin J Am Soc Nephrol 2015;10:592-600.

[6] Wang F, Zhang Y, Mao J, et al. Spectrum of mutations in Chinese children with steroid-resistant nephrotic syndrome. Pediatr Nephrol 2017;32:1181-1192.

[7] Nagano C, Yamamura T, Horinouchi T, et al. Comprehensive genetic diagnosis of Japanese patients with severe proteinuria. Sci Rep 2020;10:270.

[8] Hinkes BG, Mucha B, Vlangos CN, et al.; Arbeitsgemeinschaft für Paediatrische Nephrologie Study Group. Nephrotic syndrome in the first year of life: two thirds of cases are caused by mutations in 4 genes (NPHS1, NPHS2, WT1, and LAMB2). Pediatrics 2007;119:e907-e919.

[9] Lee JH, Han KH, Lee H, et al. Genetic basis of congenital and infantile nephrotic syndromes. Am J Kidney Dis 2011; 58:1042-1043.

[10] Gbadegesin R, Hinkes BG, Hoskins BE, et al. Mutations in PLCE1 are a major cause of isolated diffuse mesangial sclerosis (IDMS). Nephrol Dial Transplant 2008;23:1291-1297.

[11] Santín S, Tazón-Vega B, Silva I, et al.; FSGS Spanish Study Group. Clinical value of NPHS2 analysis in early- and adultonset steroid-resistant nephrotic syndrome. Clin J Am Soc Nephrol 2011;6:344-354.

[12] Cho HY, Lee JH, Choi HJ, et al. WT1 and NPHS2 mutations in Korean children with steroid-resistant nephrotic syndrome. Pediatr Nephrol 2008;23:63-70.

[13] Sako M, Nakanishi K, Obana M, et al. Analysis of NPHS1, NPHS2, ACTN4, and WT1 in Japanese patients with congenital nephrotic syndrome. Kidney Int 2005;67:1248-1255.

[14] Lipska BS, Ranchin B, Iatropoulos P, et al.; PodoNet Consortium. Genotype-phenotype associations in WT1 glomerulopathy. Kidney Int 2014;85:1169-1178.

[15] Ruf RG, Schultheiss M, Lichtenberger A, et al.; Members of the APN Study Group. Prevalence of WT1 mutations in a large cohort of patients with steroid-resistant and steroidsensitive nephrotic syndrome. Kidney Int 2004;66:564-570.

[16] Yao T, Udwan K, John R, et al. Integration of genetic testing and pathology for the diagnosis of adults with FSGS. Clin J Am Soc Nephrol 2019;14:213-223.

[17] Hildebrandt F, Heeringa SF. Specific podocin mutations determine age of onset of nephrotic syndrome all the way into adult life. Kidney Int 2009;75:669-671.

[18] Barisoni L, Diomedi-Camassei F, Santorelli FM, et al. Collapsing glomerulopathy associated with inherited mitochondrial injury. Kidney Int 2008;74:237-243.
[19] Park E, Ahn YH, Kang HG, et al. COQ6 mutations in children with steroid-resistant focal segmental glomerulosclerosis and sensorineural hearing loss. Am J Kidney Dis 2017; 70:139-144.

[20] Diomedi-Camassei F, Di Giandomenico S, Santorelli FM, et al. COQ2 nephropathy: a newly described inherited mitochondriopathy with primary renal involvement. J Am Soc Nephrol 2007;18:2773-2780.

[21] Preston R, Stuart HM, Lennon R. Genetic testing in steroidresistant nephrotic syndrome: why, who, when and how? Pediatr Nephrol 2019;34:195-210.

[22] Desbats MA, Lunardi G, Doimo M, Trevisson E, Salviati L. Genetic bases and clinical manifestations of coenzyme Q10 (CoQ 10) deficiency. J Inherit Metab Dis 2015;38:145-156.

[23] Heeringa SF, Chernin G, Chaki M, et al. COQ6 mutations in human patients produce nephrotic syndrome with sensorineural deafness. J Clin Invest 2011;121:2013-2024.

[24] Rötig A, Appelkvist EL, Geromel V, et al. Quinone-responsive multiple respiratory-chain dysfunction due to widespread coenzyme $Q_{10}$ deficiency. Lancet 2000;356:391-395.

[25] Ashraf S, Gee HY, Woerner S, et al. ADCK4 mutations promote steroid-resistant nephrotic syndrome through CoQ10 biosynthesis disruption. J Clin Invest 2013;123:5179-5189.

[26] Montini G, Malaventura C, Salviati L. Early coenzyme Q10 supplementation in primary coenzyme Q10 deficiency. $N$ Engl J Med 2008;358:2849-2850.

[27] Park E, Ahn YH, Kang HG, Miyake N, Tsukaguchi H, Cheong HI. NUP107 mutations in children with steroid-resistant nephrotic syndrome. Nephrol Dial Transplant 2017; 32:1013-1017.

[28] Park E, Kang HG, Choi YH, et al. Focal segmental glomerulosclerosis and medullary nephrocalcinosis in children with ADCK4 mutations. Pediatr Nephrol 2017;32:15471554.

[29] Bergmann C. Advances in renal genetic diagnosis. Cell Tissue Res 2017;369:93-104.

[30] Harita Y. Application of next-generation sequencing technology to diagnosis and treatment of focal segmental glomerulosclerosis. Clin Exp Nephrol 2018;22:491-500.

[31] Jungraithmayr TC, Hofer K, Cochat P, et al. Screening for NPHS2 mutations may help predict FSGS recurrence after transplantation. J Am Soc Nephrol 2011;22:579-585.

[32] Kuusniemi AM, Qvist E, Sun Y, et al. Plasma exchange and retransplantation in recurrent nephrosis of patients with congenital nephrotic syndrome of the Finnish type (NPHS1). Transplantation 2007;83:1316-1323. 
[33] Trautmann A, Lipska-Ziętkiewicz BS, Schaefer F. Exploring the clinical and genetic spectrum of steroid resistant nephrotic syndrome: the PodoNet registry. Front Pediatr 2018;6:200.

[34] Lipska BS, Iatropoulos P, Maranta R, et al.; PodoNet Consortium. Genetic screening in adolescents with steroidresistant nephrotic syndrome. Kidney Int 2013;84:206-213.

[35] Xue Y, Ankala A, Wilcox WR, Hegde MR. Solving the molecular diagnostic testing conundrum for Mendelian disorders in the era of next-generation sequencing: single-gene, gene panel, or exome/genome sequencing. Genet Med 2015;17: 444-451.

[36] Lovric S, Ashraf S, Tan W, Hildebrandt F. Genetic testing in steroid-resistant nephrotic syndrome: when and how? Nephrol Dial Transplant 2016;31:1802-1813.

[37] National Cancer Institute. NCI dictionary of genetics terms [Internet]. Bethesda (USA): National Cancer Institute, c2019 [cited 2019 Dec 27]. Available from: https://www. cancer.gov/publications/dictionaries/genetics-dictionary/ def/phenocopy.

[38] Gast C, Pengelly RJ, Lyon M, et al. Collagen (COL4A) muta- tions are the most frequent mutations underlying adult focal segmental glomerulosclerosis. Nephrol Dial Transplant 2016;31:961-970.

[39] Wang X, Anglani F, Beara-Lasic L, et al.; Investigators of the Rare Kidney Stone Consortium. Glomerular pathology in dent disease and its association with kidney function. Clin J Am Soc Nephrol 2016;11:2168-2176.

[40] Barua M, Stellacci E, Stella L, et al. Mutations in PAX2 associate with adult-onset FSGS. J Am Soc Nephrol 2014;25: 1942-1953.

[41] Jaurretche S, Antongiovanni N, Perretta F. Fabry nephropathy. Role of nephrologist and clinical variables associated with the diagnosis. Nefrologia 2019;39:294-300.

[42] Schaefer F. "It's in your genes": exome sequencing enables precision diagnostics in proteinuric kidney diseases. Clin $J$ Am Soc Nephrol 2020;15:10-12.

[43] Landini S, Mazzinghi B, Becherucci F, et al. Reverse phenotyping after whole-exome sequencing in steroid-resistant nephrotic syndrome. Clin J Am Soc Nephrol 2020;15:89100. 